\title{
Centennial Center Spotlight
}

\section{Make Use of The Centennial Center's Visiting Scholar Shared Workspace!}

Amanda Grigg, Associate Director, The Centennial Center for Political Science \& Public Affairs

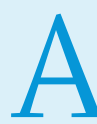

PSA's Centennial Center for Political Science and Public Affairs offers workspace in DC for visiting scholars. The Visiting Scholar space is located in APSA's headquarters and is designed to facilitate research and provide a quiet atmosphere for study, and includes access to wifi, printing, political science literature, and complementary coffee and tea. The shared workspace was recently upgraded with new furniture to accomodate even more scholars in the space. The new furniture and layout can be seen in the accompanying pictures. The Visiting Scholar space is conveniently located near the Dupont Circle Metro Station and is a short metro ride away from downtown DC, the Library of Congress, and Capitol Hill.

Political science graduate students and faculty from the US and abroad are encouraged to make use of the space whenever necessary. Visits can range from one day to several months. To schedule a visit, please complete the form at: https://apsa.wufoo.com/forms/apsavisiting-scholar-program-application/. -

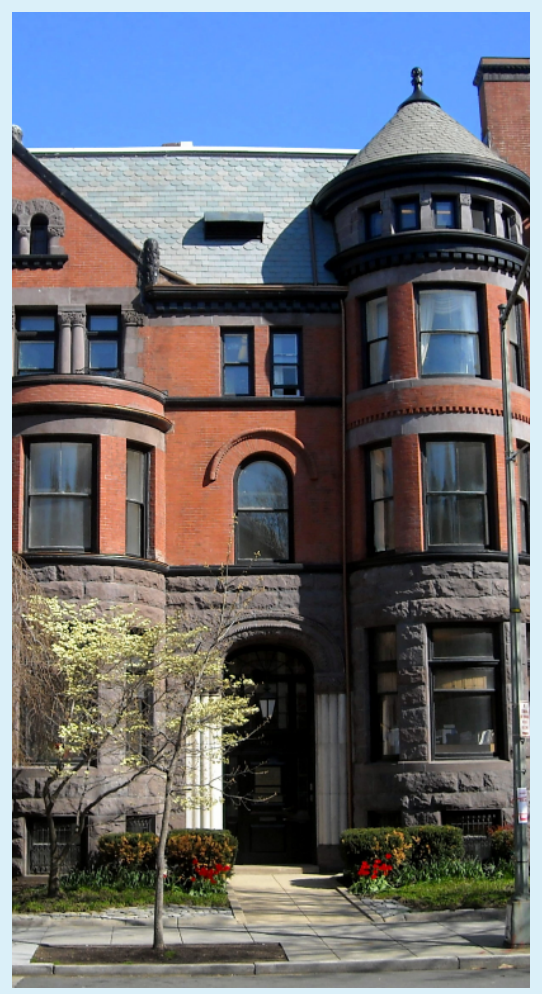

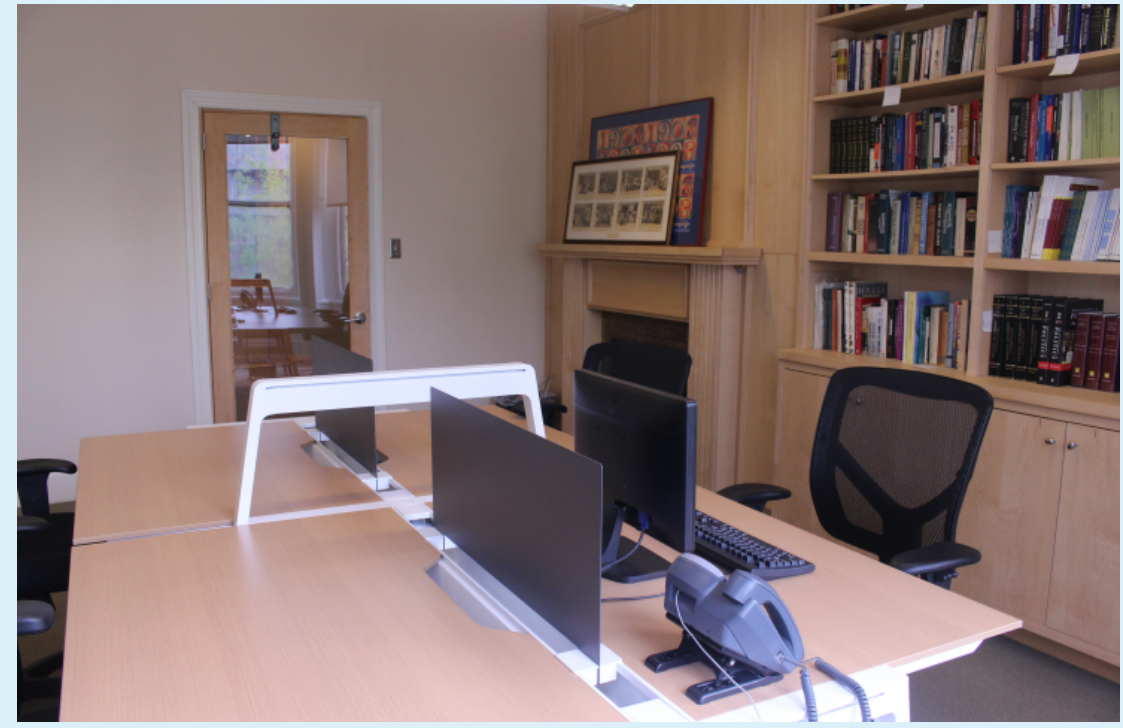

"Working as an APSA Visiting Scholar has allowed me to make great progress in my research and writing. The Centennial Center offers a quiet space to write, while the nearby Metro makes it easy to make trips around the city for interviews and visits to the Library of Congress."

-Professor Matthew Green, The Catholic University of America

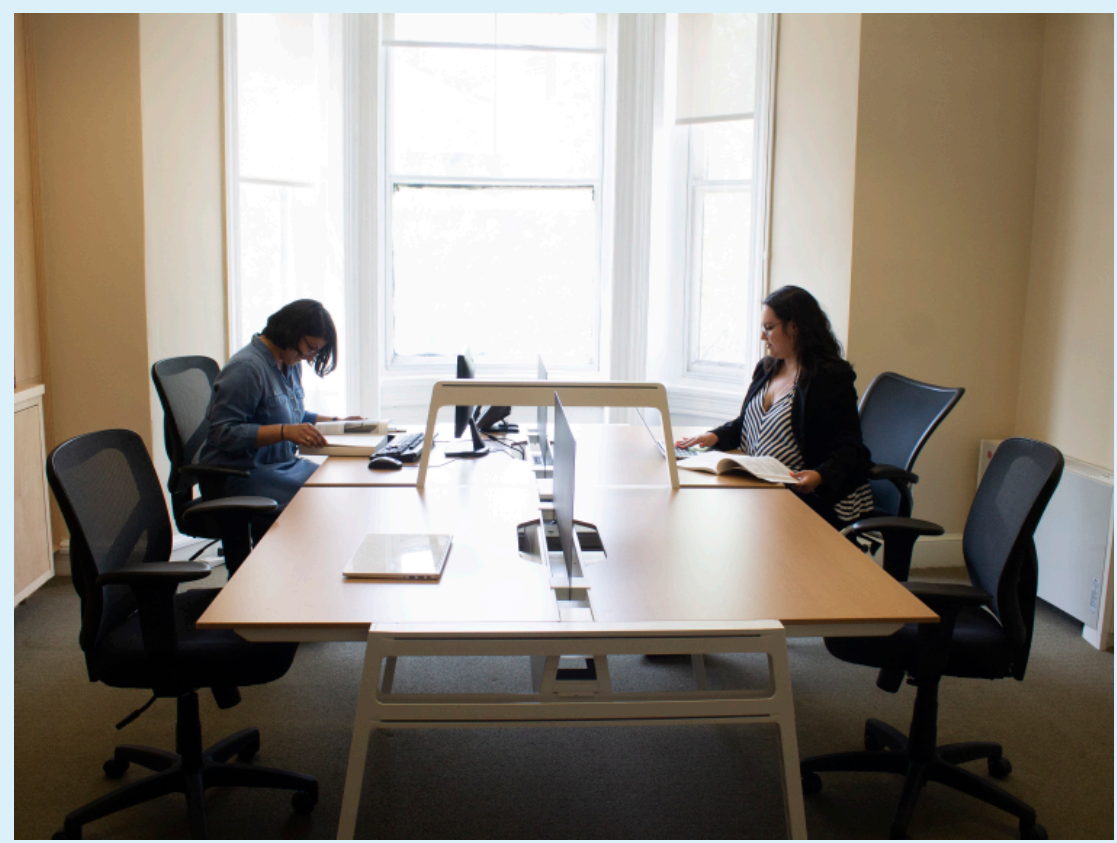

